\title{
Costs of an Aedes aegypti vector control program
}

\section{Custos de um programa de controle de vetores do Aedes aegypti}

\section{Costos de un programa de control de vectores de Aedes aegypti}

Sora Yasri 1

Viroj Wiwanitkit 2

doi: 10.1590/0102-311X00242318

Dear Editors,

We have read the publication on Costs of an Aedes aegypti Vector Control Program in Municipalities in Colombia: A Case Study in Girón and Guadalajara de Buga, 2016 with great interest 1. Salinas-López et al. concluded that "the predominant cost strategies were chemical spraying of adult mosquitos, accounting for 26\% of the total costs in Girón and 47\% in Guadalajara de Buga, with personnel representing 40\% of the total costs for this strategy in Girón and 66\% of the operating costs in Guadalajara de Buga" (p. 1). We would like to share our ideas about this issue. The cost of insecticide is usually mentioned as a main cost for mosquito control. Nevertheless, there are other indirect costs that might be forgotten. Good examples are the cost of health promotion, salary of health care workers, transport costs for mosquito control, etc. As noted in a report from Cuba, although direct medical costs are the main costs for mosquito control, direct non-medical costs and indirect costs should not be forgotten 2 . Baly et al. noted that the direct medical cost was $62 \%$ whereas the direct non-medical cost was $9 \%$ and the indirect cost was $29 \% 2$.

\section{Contributors}

Both authors contributed equally to the preparation of the text.

\section{Additional informations}

ORCID: Sora Yasri (0000-0001-8292-6656); Viroj Wiwanitkit (0000-0003-1039-3728).

\section{References}

1. Salinas-López MA, Soto-Rojas VE, Ocampo CB. Costs of an Aedes aegypti vector control program in municipalities in Colombia: a case study in Girón and Guadalajara de Buga, 2016. Cad Saúde Pública 2018; 34:e00044518.

2. Baly A, Toledo ME, Rodriguez K, Benitez JR, Rodriguez M, Boelaert M, et al. Costs of dengue prevention and incremental cost of dengue outbreak control in Guantanamo, Cuba. Trop Med Int Health 2012; 17:123-32.
${ }_{1}$ KMT Primary Care

Center, Bangkok,

Thailand.

2 Dr. DY Patil University,

Pube, India.

\section{Correspondence}

S. Yasri

KMT Primary Care Center. Bangkok / Bangkok - 10150, Thailand.

sorayasri@outlook.co.th 